\title{
Technical Note \\ Reduction in Blockage Property of UV-Blocking Greenhouse Covering Material: In Situ and Lab Measurement Comparison
}

\author{
Chryssoula Papaioannou ${ }^{1}$, Nikolaos Katsoulas ${ }^{2, * \mathbb{C}}$ and Evangelini Kitta ${ }^{2}$ \\ 1 Department of Agrotechnology, School of Agricultural Sciences, University of Thessaly, 41500 Larisa, Greece; \\ chpapa@uth.gr \\ 2 Department of Agriculture Crop Production and Rural Environment, School of Agricultural Sciences, \\ University of Thessaly, Fytokou Str., 38446 Volos, Greece; ekitta@uth.gr \\ * Correspondence: nkatsoul@uth.gr; Tel.: +30-2421093249
}

check for

updates

Citation: Papaioannou, C.; Katsoulas,

N.; Kitta, E. Reduction in Blockage

Property of UV-Blocking Greenhouse

Covering Material: In Situ and Lab

Measurement Comparison.

AgriEngineering 2022, 4, 171-178.

https://doi.org/10.3390/

agriengineering 4010012

Academic Editor: Chrysoula

Nikita-Martzopoulou

Received: 21 December 2021

Accepted: 17 February 2022

Published: 21 February 2022

Publisher's Note: MDPI stays neutral with regard to jurisdictional claims in published maps and institutional affiliations.

Copyright: (C) 2022 by the authors. Licensee MDPI, Basel, Switzerland. This article is an open access article distributed under the terms and conditions of the Creative Commons Attribution (CC BY) license (https:// creativecommons.org/licenses/by/ $4.0 /)$.

\begin{abstract}
The goal of this research was to compare and evaluate the measurements taken by different instruments regarding alterations while varying the ultraviolet (UV)-blocking property of cladding material during its usage under real greenhouse conditions. The UV-blocking covering material, low-density polyethylene (LDPE), is enriched with additives that are scattered in several layers during the manufacturing process, resulting in the reinforcement of its properties mechanically as well as optically. The duration of this study was three years, and the instruments used were: (a) sensors measuring the UV radiation reaching the earth's surface in its A and B components; and (b) a portable spectroradiometer capable of measuring the transmissivity of a material, only in the UV-A region. Three covering materials were used with different UV radiation transmissivity. The transmittance was measured both in the laboratory (on samples taken from the roof) and in the field (where the greenhouses were located). Equations were defined to describe the variation in UV radiation transmission increase rate as a function of field exposure time. Lastly, it is important to note that the specific UV radiation sensors were extremely accurate.
\end{abstract}

Keywords: transmissivity instrumentation; greenhouse cover properties; polyethylene; UV-blocking

\section{Introduction}

The use of ultraviolet (UV)-blocking material in greenhouse coverings leads to a decrease in pesticide usage in agricultural cultivation and production, which is one of the main goals of farming today. Adopting this type of material leads to sustainability and the preservation of consumer health, as it is a green solution that simply changes the environment of a plant, making it uncomfortable for its enemies. In doing this, we can avoid existing or new chemical inventions that create more problems than solutions. Many scandals have been exposed and chemicals used in plant nutrition or pest control have been withdrawn after being characterized as dangerous for the health of humans and for the environment. Many research reports [1-6] have concluded that the use of UV-absorbing films leads to a decrease in insect populations and fungal diseases in greenhouses.

However, it is worth noting that a total absence of UV can lead to a reduction in secondary plant compounds, such as phenolic compounds, flavonoids and carotenoids [7]. The blockage of UV solar radiation via glazing is achieved during the blowing process, in which low-density polyethylene (LDPE) is enriched with a large amount of additives, present in every plastic material, to combat UV radiation. Without these additives, exposure to solar radiation would destroy LDPE in a very short period [8]. Apart from these additives that offer UV stabilization, other additives are present in the matrix formation of covering material that are relevant to other regions of the solar spectrum, i.e., infrared (IR), near-IR (NIR) while fluorescent, etc. [9].

However, all the improved optical properties that a covering material may have when it is new are degraded after sun exposure. The ageing process of the film is unavoidable, 
affecting both its mechanical properties, such as the strength of the material (in tension, tear, etc.) [10], as well as its radiometric properties [11]. Ideally, the properties of a cover would last throughout its lifespan until the end of its use [12]. However, researchers have stated that the UV-absorbing additives in a polymer matrix have the tendency to lose their UV-blocking property over time, as their low compatibility with the polymeric matrix causes them to be lost through migration. [13]. Until now, further investigation has been needed regarding the effect of ageing on the duration of UV radiation blocking.

\section{Materials and Methods}

\subsection{Greenhouse Facilities}

Three covering materials $180 \mu \mathrm{m}$ thick were tested, consisting of LDPE with equal amounts of infrared (IR), anti-fog (AF) and ethyl vinyl acetate (EVA) additives, and differing in UV-stabilizer content (additives were added via melt blending). The cover transmissivity of UV radiation was initially 5\%, 3\% and $0 \%$ in UV-5\%, UV-3\% and UV-0\% greenhouses, respectively. In fact, the cover of greenhouse UV-0\% was a UV-blocking material. The above data for the transmittances of UV radiation was provided by the manufacturer and verified by us through measurements (in the laboratory) before the installation of the material. Venlo-type constructions with a N-S orientation were used $(8 \mathrm{~m} * 20 \mathrm{~m})$, and located in the premises of the University of Thessaly (latitude $39^{\circ} 22^{\prime}$, longitude $22^{\circ} 44^{\prime}$, altitude $85 \mathrm{~m}$ ) (Figure 1). The height was $3.5 \mathrm{~m} / 2.5 \mathrm{~m}$ (top/wall), and the duration of the experiment was three years.
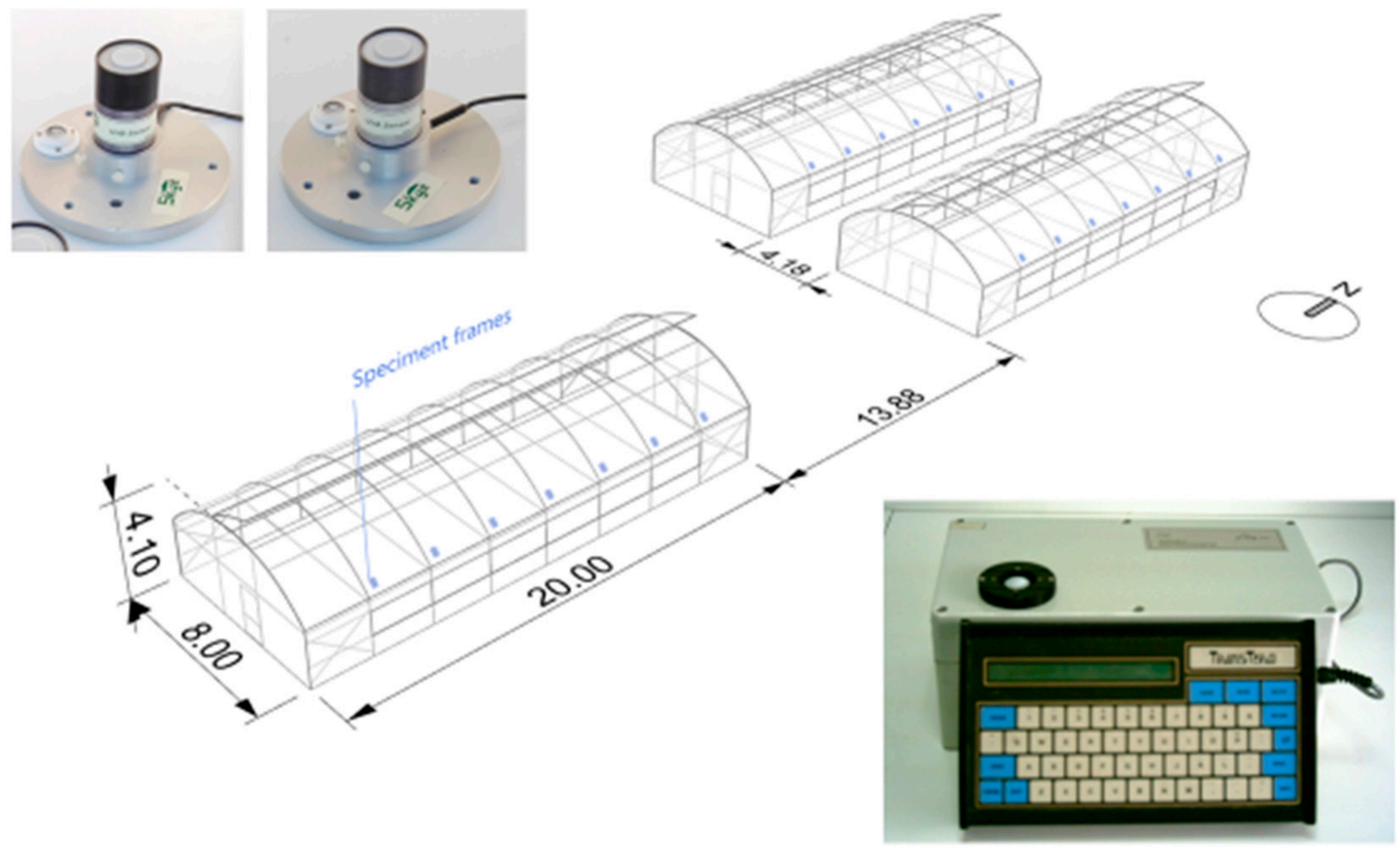

Figure 1. Layout and orientation of the experimental greenhouses. Specimen frames indicate places on the greenhouse roofs where samples of the material were cut off and their transmittance was evaluated. In situ measurements were performed with ultraviolet (UV)-B and UV-A radiation sensors (on the top-left), while a LI-COR-1800 instrument (bottom-right) was used in the laboratory measurements.

\subsection{Measurements}

During the 34-month experimental period, measurements of the spectral transmittance of the three cladding materials were taken as follows: 
(a) Laboratory measurements were conducted using a LI-COR portable spectroradiometer (LI-1800), (Figure 1), measuring in the range of $350 \mathrm{~nm}$ to $1100 \mathrm{~nm}$, equipped with a $10 \mathrm{~W}$ glass halogen lamp and an external integrating sphere (LI-1800-12S) internally coated with barium sulphate. Details concerning the instrument and measuring technique are given by Kittas and Baille (1998) [14]. The samples were cut off each greenhouse roof (same position) and washed.

(b) In-situ measurements were conducted using UV-B (290-315 $\mathrm{nm}, \mathrm{W} \mathrm{m}^{-2}$, model SKU 430, Skye Instruments Ltd, U.K.) and UV-A sensors (315-380 nm, $\mathrm{W} \mathrm{m}^{-2}$, model SKU 420, Skye Instruments Ltd, U.K.) installed inside and outside each greenhouse (Figure 1). Values were collected on a data logger system (model DL3000, Delta-T Devices, Cambridge, U.K.) every $30 \mathrm{~s}$, and 10-min average values were recorded.

\section{Results}

The evolution of the UV radiation transmissivity of the covering films as captured by laboratory measurements is presented in Figure 2. Specifically, laboratory measurements were performed on 1 December of the first year (first month of the experiment), 1 December of the second year (24th month of the experiment) and 1 October of the third year (33rd month of experiment).

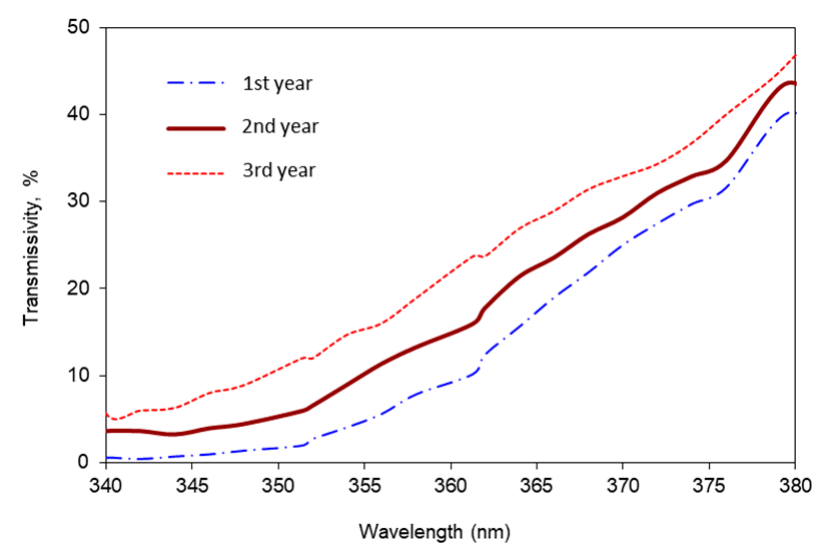

(a)

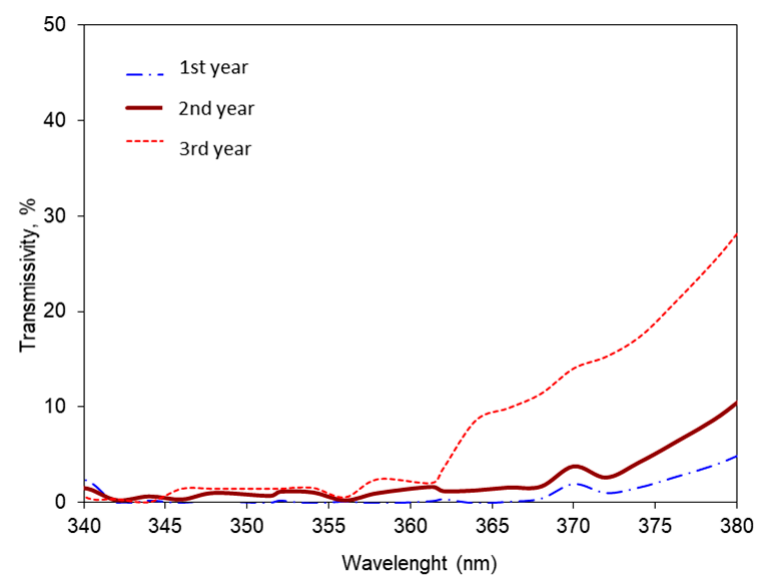

(b)

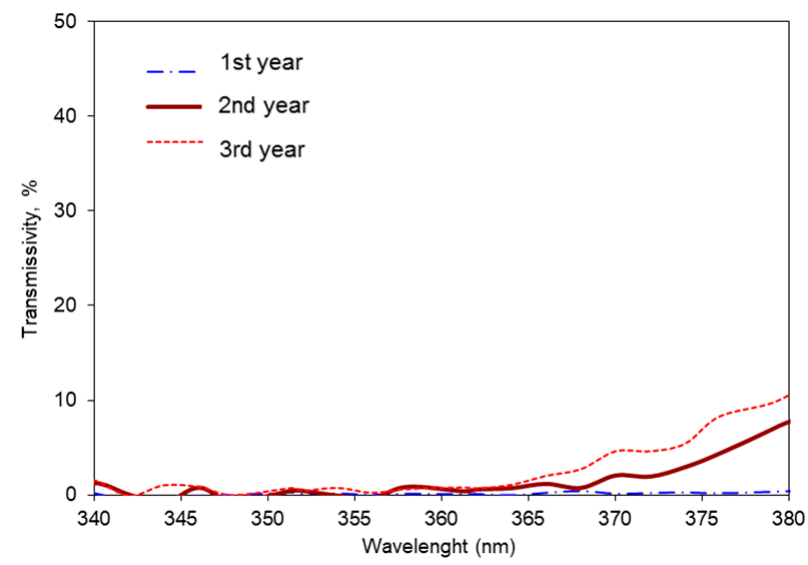

(c)

Figure 2. UV-A transmission coefficient evolution of the covering films for three years for: (a) UV-5\% film; (b) UV-3\% film; and (c) UV-0\% film.

The results revealed that the UV-A radiation transmissivity in all tested claddings increased after their outdoor exposure (Figure 2). This increase was not the same for every material. At least one cover (UV-0\%) expressed different behavior. 
The cover of the UV-0\% greenhouse, characterized by the highest concentration of UV stabilizers, showed a slower increase. We may conclude that the alteration in transmissivity of a covering material depends on the amount of UV absorbers that are presented in its initial master batch formation during manufacturing.

The same trend was found in the other set of measurements regarding the UV-A and UV-B sensor values (Figure 3). Indeed, every year, more UV radiation enriched the interior of the greenhouses. Comparing the amount of UV radiation in the two regions of UV, it can be seen that, in the lower waveband (i.e., UV-B), the cladding material showed a higher capability to block (UV-B rather than UV-A). Comparing the rhythm of transmission increase over time, it seems that, in the UV-A region, the trend is clearer, proportional to that in the UV-B region (Figure 3). In both regions, after the first year of exposure where the amounts of UV almost doubled, the increase was lower in the UV-A waveband, while for the same period in the UV-B region, the increase continued.

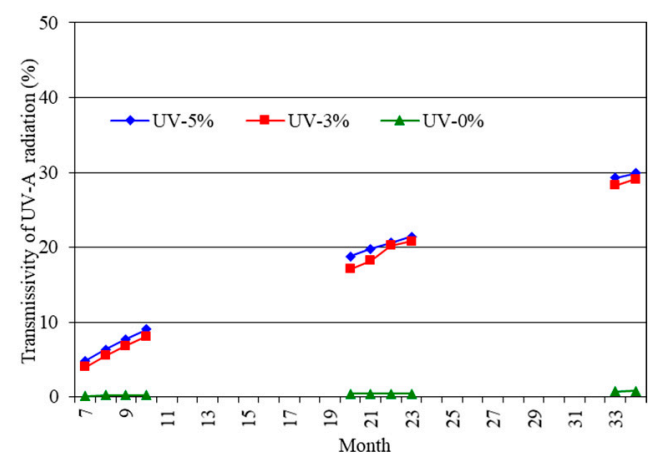

(a)

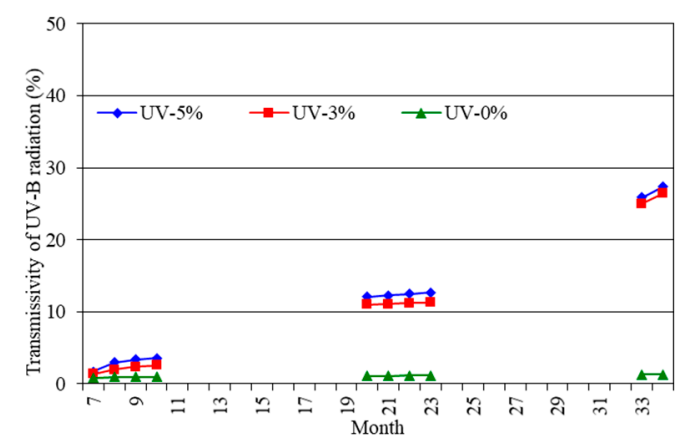

(b)

Figure 3. Monthly changes in covering material transmissivity for: (a) UV-A; and (b) UV-B radiation. The first measurement was taken seven months after the installation of the films.

In order to establish a model of covering transmissivity increase over time, we proceeded with an examination of the in situ values from the UV-A and UV-B sensors, as presented in Table 1.

Table 1. Cover transmissivity (\%) of UV radiation for A and B wavebands.

\begin{tabular}{cccccccc}
\hline & & UV-A & & \multicolumn{3}{c}{ UV-B } \\
\hline & & UV-5\% & UV-3\% & UV-0\% & UV-5\% & UV-3\% & UV-0\% \\
\hline March & & 4.8 & 4.0 & 0.1 & 1.7 & 1.4 & 0.8 \\
April & \multirow{2}{*}{ 1st year } & 6.3 & 5.5 & 0.2 & 3.0 & 2.0 & 1.0 \\
May & 7.7 & 6.8 & 0.2 & 3.4 & 2.4 & 1.0 \\
June & & 9.0 & 0.1 & 0.2 & 3.6 & 2.6 & 1.0 \\
\hline April & & 18.8 & 17.1 & 0.4 & 12.1 & 11.0 & 1.1 \\
May & \multirow{2}{*}{ 2nd year } & 19.8 & 18.2 & 0.4 & 12.3 & 11.1 & 1.1 \\
June & & 20.6 & 20.2 & 0.4 & 12.5 & 11.2 & 1.2 \\
July & & 21.4 & 20.8 & 0.4 & 12.7 & 11.3 & 1.2 \\
\hline May & \multirow{2}{*}{ 3rd year } & 29.3 & 28.3 & 0.7 & 25.9 & 25.0 & 1.3 \\
June & & 29.9 & 29.1 & 0.8 & 27.4 & 26.4 & 1.3 \\
\hline
\end{tabular}

According to Table 1, the UV-A radiation transmissivity of the UV-5\% cover increased from $4.8 \%$ (first year) to $29.9 \%$ (third year), which is a 6.2 -fold increase. In the UV-3\% greenhouse, the increase was 7.3 -fold $(4.0 \%$ to $29.1 \%)$. In the case of the UV-blocking material (UV-0\% greenhouse), the increase was the highest (an 8.0-fold increase, from 0.1 to $0.8 \%$ ).

Therefore, from among the three covers, it appears that greenhouse UV- $0 \%$ cover had the greatest increase in UV-A transmissivity (6.3 vs. 7.3 vs. 8.0 , for greenhouses UV-5\%, 
UV-3\% and UV-0\%, respectively); however, this greenhouse (UV-0\%) did not reach (not even after 34 months of exposure) the high transmissivity level that the UV-5\% greenhouse (for UV-A radiation) had when it was new ( $0.8 \%$ vs. $4.8 \%$, Table 1$)$.

At the same time, regarding UV-B radiation transmissivity (Table 1), the cover of the UV-5\% greenhouse showed a 16.1 -fold increase $(1.7 \%$ to $27.4 \%)$ vs. a 18.9 -fold increase $(1.4 \%$ to $26.4 \%$ ) and a 1.6 -fold increase $(0.8 \%$ to $1.3 \%$ ) for the UV-3\% and UV- $0 \%$ greenhouses, respectively.

Finally, from among the three covers, it appears that greenhouse UV-3\% had the greatest increase in UV-B transmissivity (16.1\% vs. $18.9 \%$ vs. $1.6 \%$, for greenhouses UV-5\%, $\mathrm{UV}-3 \%$ and UV-0\%, respectively); however, this greenhouse (UV-0\%) did not reach (even after 34 months of exposure) the high transmissivity level that the UV-3\% greenhouse cover had for UV-B radiation when it was new (1.3\% vs. $1.4 \%$, Table 1$)$.

For each material, an equation was defined to describe the variation in UV radiation transmissivity increase rate as a function of field exposure time (month) (presented in Table 2), applying a linear regression in the form $y=a x+b$, where $y_{A}$ is the transmissivity in UV-A radiation and $y_{B}$ is the transmissivity in UV-B radiation expressed in $\%$, and $x$ is the period of outside exposure (months).

Table 2. Variables and constant numbers expressing the linear regression representing the evolution of UV radiation transmissivity of the covering materials after being exposed in field conditions (months).

\begin{tabular}{|c|c|c|c|c|}
\hline & $\mathbf{a}$ & b (Constant) & $\mathbf{R}^{2}$ & Greenhouses \\
\hline \multirow{3}{*}{ yA } & 0.188 & 1.124 & 0.99 & UV-5\% \\
\hline & 0.226 & 1.107 & 0.99 & UV-3\% \\
\hline & 0.216 & 1.082 & 0.94 & UV-0\% \\
\hline \multirow{3}{*}{$\mathrm{y}_{\mathrm{B}}$} & 0.543 & -0.217 & 0.97 & UV-5\% \\
\hline & 0.658 & -1.040 & 0.96 & UV-3\% \\
\hline & 0.015 & 1.201 & 0.95 & UV-0\% \\
\hline
\end{tabular}

As can be seen in Table 2, among the three covering materials, parameter a varies slightly $(0.188-0.226)$ for UV-A, while for the UV-B waveband, the range of values is 0.015-0.658, which means that the films' behavior with regard to the specific optical property modification is more uniform in the UV-A than in the UV-B waveband $\left(\mathrm{R}^{2}\right.$ values are also higher).

Similar trends of increased UV-A radiation transmissivity values were also observed for the covers from the in situ measurements obtained in the laboratory using a spectroradiometer (Table 3).

Table 3. Mean values of calculated film transmissivity, $\%$ in $300-380 \mathrm{~nm}$ wavelength range (laboratory measurements).

\begin{tabular}{ccccc}
\hline & 0 Months & 24 Months & 33 Months & 36 Months \\
\hline UV-5\% & 6.7 & 24.3 & 33.4 & 40.8 \\
UV-3\% & 5.3 & 23.3 & 31.8 & 33.6 \\
UV-0\% & 0.1 & 1.3 & 1.4 & 1.7 \\
\hline
\end{tabular}

After the comparison of values shown in Tables 1 and 3, it can be concluded that the increase in cover transmissivity due to ageing was lower (approximately 10\%, Figure 4) when comparing field with laboratory measurements. Similar results were also observed for the UV-3\% and UV-0\% greenhouses (data not shown). 


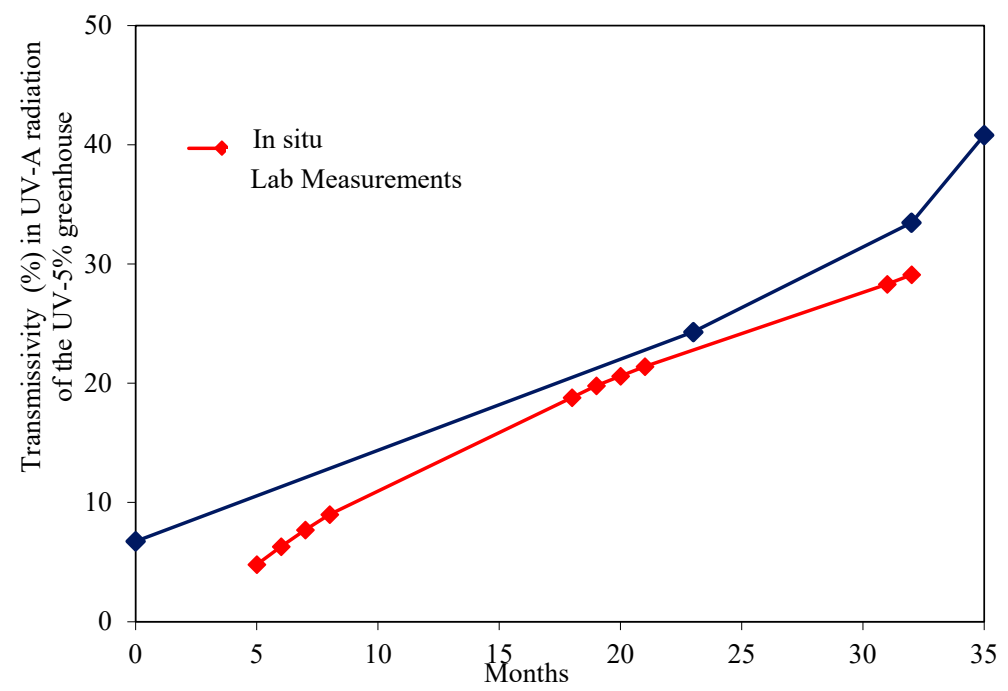

Figure 4. Comparison of laboratory measurements and in situ measurements for the UV-5\% film in the UV-A region.

\section{Discussion}

When the alteration in transmissivity of the whole spectrum of UV radiation for covers was evaluated in a survey carried out in Spain [15], it was reported that the optical properties of covering films were worse after 158 days of outdoor exposure, especially for those with UV-blocking characteristics. These findings are in accordance with ours regarding one of our films (UV-3\%). The UV-blocking film that was tested here (the cover of the UV- $0 \%$ greenhouse) was found to retain its UV-blocking characteristics. In the US, Giacomelli et al. [16] pointed out that the transmissivity of glazing for wavebands between 300 and $1100 \mathrm{~nm}$ decreased for new and weathered (four-year-old) polyethylene films. This is true in the case of our findings regarding the UV-5\% and UV-3\% greenhouses, where the levels of UV radiation increased over time.

If we distinguish the alteration in transmissivity of the covers separately in the two different regions of UV radiation (i.e., UV-A and UV-B wavebands), after the examinations of the measured values, we found that the alteration was greater in the UV-B than the UV-A band. This part (UV-B) belongs in the lower part of UV radiation, compared with UV-A. To our knowledge, this is the first time that differences in the alteration of UV radiation transmissivity due to weathering has been reported. Regarding other levels of solar radiation reaching the interior of greenhouses, relative conclusions have been found. For example, in the case of photosynthetically active radiation, it has been stated that there are distinct differences between new and weathered film, particularly in the lower photosynthetically active radiation (PAR) region, where the difference was greater $[16,17]$. We traced greater differences in the UV transmissivity of the covers for the lower region of UV radiation, the UV-B waveband.

Similarly, from a comparison of laboratory and in situ measurements, it was found that there are differences. In situ measurements underestimate transmission values. These measurements were taken using sensors installed in the center of the enclosure, within plant greenhouses. The geometry of the structures, the dust, and the presence of plants increased the diffusive component of the incoming UV radiation. This may explain the differences in those values and the values taken under laboratory conditions with an integrating sphere, where the samples were cleaned and the beam radiation illuminated the sample perpendicular to its surface. Therefore, the resulting transmissivity was maximized. In both cases, an alteration in UV transmissivity over time is unquestionably evident.

In addition, the fact that the cover of the UV- $0 \%$ greenhouse, which was a completely blocking material, remained as an opaque cladding to UV radiation after 34 months, has important implications for the sustainability of the ecosystem. First, for most plant 
species cultivated under UV-blocking material photosynthesis, stomatal conductance and transpiration are enhanced [7]. Moreover, plant height and leaf area seem to be positively affected by UV-blocking cladding materials, and the same occurs for yield and growth characteristics. Lastly, the application of UV-blocking materials creates a particular light modification in the plant environment, leading to better canopy light-use efficiency [18]. Apart from the relatively beneficial effects on plant behavior, the use of a UV-blocking film is advantageous mainly because, with an almost non-existent additional buying cost compared with common PE film, it results in lower pest and disease impacts on the crop, a lower pesticide load on the crop, and therefore lower production costs [2,7,19].

\section{Conclusions}

The measurements of cover transmissivity due to ageing are different when comparing field with laboratory values. In situ measurements using sensors installed in the center of a greenhouse underestimate the transmission by almost $10 \%$. The levels of UV radiation inside a greenhouse covered by a completely UV-blocking material increases over time, but its blocking property is retained after three years of exposure in outdoor conditions. This is evident regardless of the way that it is measured. It is important to note that, for reliable measurements within the UV spectrum range, UV-A and UV-B sensors, which are designed precisely for this purpose, should be used. Similarly, greater differences in UV transmissivity alteration for covers are present in the lower region of UV radiation; that is, the UV-B region rather than the UV-A region of the solar spectrum.

Author Contributions: Conceptualization, C.P. and N.K.; methodology, C.P.; investigation, C.P.; data curation, C.P. and E.K.; writing-original draft preparation, C.P. and E.K.; writing-review and editing, C.P., N.K. and E.K. All authors have read and agreed to the published version of the manuscript.

Funding: This research received no external funding.

Institutional Review Board Statement: Not applicable.

Informed Consent Statement: Not applicable.

Data Availability Statement: Not applicable.

Conflicts of Interest: The authors declare no conflict of interest.

\section{References}

1. Antignus, Y.; Lapidot, M.; Hadar, D.; Messika, Y.; Cohen, S. Ultraviolet-absorbing screens serve as optical barriers to protect crops from virus and insect pests. J. Econ. Entomol. 1998, 9, 1401-1405. [CrossRef]

2. Costa, H.S.; Robb, K.L. Effects of ultraviolet-absorbing greenhouse plastic films on flight behavior of Bemisia argentifolii (Homoptera: Aleyrodidae) and Frankliniella occidentalis (Thysanoptera: Tripidae). J. Econ. Entomol. 1999, 92, 557-562. [CrossRef]

3. Secker-Esquira, I. Effect of UV absorbing plastic covers on bumblebees in tomato greenhouses. In Proceedings of the 15th International Congress for Plastic in Agriculture, Hershey, PA, USA, 23-27 September 2000; pp. 150-151.

4. Costa, H.S.; Robb, K.L.; Wilen, C.A. Fields trials measuring the effects of ultraviolet-absorbing greenhouse plastic films on insect populations. J. Econ. Entomol. 2002, 95, 113-120. [CrossRef] [PubMed]

5. Monci, F.; García-Andrés, S.; Sánchez, F.; Moriones, E.; Espí, E.; Salmerón, A. Tomato Yellow Leaf Curl disease control with UV-blocking plastic covers in commercial plastichouses of southern Spain. Acta Hortic. 2004, 633, 537-542. [CrossRef]

6. González, A.; García-Alonso, Y.; Espí, E.; Fontecha, A.; Salmerón, A. Viral diseases control with UV-blocking films in greenhouses of southern Spain. Acta Hortic. 2004, 659, 331-338. [CrossRef]

7. Katsoulas, N.; Bari, A.; Papaioannou, C.H. Plant responses to UV blocking greenhouse covering materials: A review. Agronomy 2020, 10, 1021. [CrossRef]

8. Dilara, P.A.; Briassoulis, D. Degradation and stabilization of Low-density Polyethylene Films used as Greenhouse Covering Materials. Review Paper. J. Agric. Eng. Res. 2000, 76, 309-321. [CrossRef]

9. Kittas, C.; Katsoulas, N.; Katsoupa, M.; Papaioannou, C.H. Test of a greenhouse covered by polyethylene film that reflects near infrared radiation. Acta Hortic. (ISHS) 2012, 956, 507-513. [CrossRef]

10. Srivastava, D. Study of aging characteristics of ternary blends of polyethylenes-II. J. Polym. Environ. 2004, 12, 27-33. [CrossRef] 
11. Scarascia Mugnozza, G.; Vox, G.; Stefani, L. Effect of the pesticides on the degradation of EVA plastic films for greenhouse covering. In Proceedings of the 15th International Congress for Plastics in Agriculture, Hershey, PA, USA, 23-27 September 2000; Siegel, R., Howell, J., Eds.; pp. 141-149.

12. Gilby, G.W. Speciality horticultural films, based on polyethylenes, for greater control of the growing environment. In Proceedings of the 11th International Congress on the Use of Plastics in Agriculture, New Delhi, India, 26 February-2 March 1990; pp. G67-G73.

13. Espí, E.; Salmerón, A.; Fontecha, A.; García, Y.; Real, A.I. Plastic films for agricultural Applications. J. Plast. Film. Sheeting 2006, 22, 85. [CrossRef]

14. Kittas, C.; Baille, A. Determination of the spectral properties of several greenhouse cover materials. Evaluation of specific parameters related to plant response. J. Agric. Eng. Res. 1998, 71, 193-202. [CrossRef]

15. Lopez-Marin, J.; Gonzalez, A.; Egea-Gilabert, C.; Fernandez, J.A. Effect of different greenhouse covering photoselective films on yield and quality of tomato. In Proceedings of the VII Congresso Iberico de Agroingenieria y Ciencias Horticolas, Madrid, Spain, 26-29 August 2013.

16. Giacomelli, G.; Ting, K.C.; Fang, W. Wavelength Specific Transmission of PE film Greenhouse Glazing. NJAES Publication No. \#D03130-27-89. In Proceedings of the 22nd National Agricultural Plastics Congress, Montreal, QC, Canada, 21-25 May 1990; pp. 129-131.

17. William, J.R. Glazing Materials, Structural Design, and Other Factors Affecting Light Transmission in Greenhouses. In Greenhouse Glazing and Solar Radiation Transmission Workshop; Center for Controlled Environment Agriculture, Rutgers University: New Brunswick, NJ, USA, 1998.

18. Maraveas, C. Environmental sustainability of greenhouse covering materials. A Review. Sustainability 2019, 11, 6129. [CrossRef]

19. Vatsanidou, A.; Bartzanas, T.; Papaioannou, C.; Kittas, C. Efficiency of physical means of IPM on insect population control in greenhouse crops. Acta Hortic. 2011, 893, 1247-1254. [CrossRef] 